\title{
Responsible research and innovation: coming to grips with an ambitious concept
}

\author{
Martin Carrier ${ }^{1} \cdot$ Gürol Irzik $^{2}$
}

Received: 7 July 2019 / Accepted: 8 July 2019 / Published online: 13 July 2019

(c) Springer Nature B.V. 2019

\begin{abstract}
This Introduction to the Special Issue on "Responsible Research and Innovation" (RRI) outlines features of the philosophical debate about the concepts involved and summarizes the papers assembled in this issue. The topic of RRI is widely discussed in science studies and has made its way into science policy. This SI is intended to make the contributions of philosophers of science more visible. The philosophically relevant parts of the field concern, among others, the processes of public participation in science and their impact on the knowledge produced, the notion of justified public trust in science, and the idea of research pursued for the common good. Such topics bring social procedures together with epistemic and ethical considerations and thus raise philosophical challenges. RRI is subject to the tension between committing research to creating knowledge in harmony with public expectations, on the one hand, while not complying with public wishful thinking, on the other. RRI embodies a friction between serving people's aspirations and correcting people's expectations. This special issue is intended to explore the narrow pathway left between these conflicting demands.
\end{abstract}

Keywords Responsible research · Responsible innovation - Science with society · Science for society

The goal of this special issue is to explore the concept of "responsible research and innovation" (RRI) with an emphasis on philosophical challenges. The concept has gained in prominence in the past decades in various contexts. It figures significantly, for instance, in the European Horizon 2020 research framework (http://ec.europa.eu/ programmes/horizon2020/en/h2020-section/responsible-research-innovation), and is

\footnotetext{
$凶$ Gürol Irzik

irzik@sabanciuniv.edu

Martin Carrier

martin.carrier@uni-bielefeld.de

1 Department of Philosophy, Bielefeld University, Bielefeld, Germany

2 Faculty of Arts and Social Sciences, Sabanci University, Istanbul, Turkey
} 
also promoted by a number of philosophers and STS scholars (Kitcher 2001, 2011; Kourany 2003, 2010; Stilgoe et al. 2013; Van den Hoven 2014; Von Schomberg 2013). The concept of RRI can be viewed as a response to the growing public insight that science is a powerful instrument that can bring about both valuable and damaging outcomes. Surveys among science-literate audiences have brought to light that a skeptical attitude prevailed regarding the trustworthiness of research results on matters relevant to everyday life. Practice-driven research and scientific expert knowledge, related, for instance, to nutritional guidelines or the safety and efficacy of vaccines, are met with reservation and doubt. The reason often given was the bias and lack of evenhandedness of scientific studies which were said to derive from the dependence of scientists on their sponsors (see, e.g., European Commission 2010; Scientific American 2010; Wissenschaft im Dialog/Kantar Emnid 2017). RRI is intended to contribute to mitigating such skepticism and to bridging the gap between science and society. RRI is thought to bring scientific research into closer contact with the interests and values of the people and to be responsive to social needs. This approach is intended to achieve two goals at a time. The first is to retain or restore public trust in science. If the one-sidedness of the questions asked and the studies conducted are a reason for public skepticism, enlarging the range of research topics, addressing missing questions, and letting the public participate in scientific processes should serve to bolster public trust in science (Carrier 2017). The second goal starts off from the observation that various research undertakings have stalled in the past due to public criticism when implementation was imminent. As a result, costly projects, such as the introduction of genetically modified organisms (GMOs) into the European market, heavily subsidized by tax money, were never put into practice after their successful completion because of public resistance. Introducing RRI is intended to re-establish links between the researchers, policymakers, and the public and thus to either create a more welcoming attitude toward the pertinent innovations or to signal to the researchers and their sponsors early on that certain technologies are unlikely to find public support. Either way, intensifying the links between science and society can be expected to align research with social needs and thereby to strengthen the public trust in science. Philip Kitcher's widely received proposal of a "well-ordered science" seeks to apply the same recipe (Kitcher 2001; 2011).

The notion of RRI, as employed within Horizon 2020, is a broad one and includes gender equality, open access publication, ethical standards in performing experiments, and science education. These goals look rather uncontroversial. What is more challenging and ambitious from a philosophical point of view is the demand for "science with and for society." This includes, in particular, doing research in interaction with society, for one, and for the benefit of or on behalf of society, for another.

"Science with society" emphasizes the goal of implicating the public in the scientific discourse. The objective is public participation and the inclusion of non-scientists in selecting research problems. The two chiefly relevant bodies are stakeholders and the general public. Stakeholders have a specific interest in certain results; relevant bodies range from economic companies to patient groups. The general public, by contrast, are ordinary people "from the street," as it were, or the wider audience. The understanding is that social agents of these two varieties articulate a certain research demand and thus 
contribute to shaping the research agenda. ${ }^{1}$ Science operating with society proceeds in interaction with such social bodies by responding to such demand. Research in this process-oriented branch of RRI takes up socially urgent issues, transforms them into research projects, and is prepared to adjust research targets in this light. The hope is that scientific research is received in a more favorable way by a wider lay audience if the public had been granted the opportunity to affect the pathways of research.

"Science for society" means that research topics that favor social concerns or the common good are privileged. It suggests that the topics be chosen on social grounds such as practical urgency or desirability. The expected outcome of a research undertaking should be beneficial to society. This outcome-oriented understanding of RRI presupposes a normative framework that serves to identify such socially responsible research objectives. René von Schomberg has proposed to draw upon fundamental treaties of the European Union for this purpose. For instance, the "Treaty on the European Union" contains a commitment to the promotion of social justice, gender equality, health, the protection of the environment, sustainable development, and others. Such normative commitments provide a basis for favoring certain research goals (von Schomberg 2013). Accordingly, RRI is characterized by socially beneficial research agendas, which are fleshed out by certain substantive commitments. That is, RRI is not thought to be characterized by certain structural ambitions, such as enhancing the speed of innovation or the competitiveness of an economy, but rather by goals such as justice, equality, and sustainability, especially in addressing "Grand Challenges" like global warming, water and food production, and aging societies.

Stilgoe et al. (2013) and Macnaghten (2016) have elaborated a similar scheme of how the dialog of science with society can take place. They distinguish between anticipation, inclusion, reflexivity, and responsiveness. Anticipation concerns the willingness and ability of scientists to foresee likely, plausible, and possible pathways of science and technology as well as their impact on society. Although large bars of uncertainty need to be assigned to such estimates, they still help to raise the attention of researchers regarding what might come out of a research endeavor. Anticipation supplies some substance to the idea of "science for society." "Science with society" is not limited to "inclusion," i.e., participatory processes, but encompasses reflexivity, i.e., the awareness of a particular framing of an issue and of the options for approaching the matter in alternative ways. Responsiveness means that scientists are prepared to change a research endeavor according to these considerations. RRI is supposed to be characterized by such governance structures of science rather than the commitment to certain social goals.

The articles in this special issue aim to explore ways of pursuing RRI from the dual perspective of science with and for society by weaving together ontological, conceptual, epistemic, methodological and ethical aspects, and to bring to the fore its various social benefits as well as the challenges it presents.

Job Timmermans and Vincent Blok's article presents a survey of the major approaches to Responsible Research (RI) in comparison to the dominant technoeconomic innovation paradigm. According to this paradigm, innovation is predomi-

\footnotetext{
1 Unfortunately, these two groups are frequently lumped together in the RRI literature (see, for instance, Blok and Lemmens 2015). However, it certainly makes a difference whether social bodies, such as companies or patient groups, pursue vested interests or can be taken to judge in light of the common good.
} 
nantly understood as technological instead of social and discussed mostly in economic terms as contributing to economic growth rather than as serving social justice. Their comparative analysis, which focuses on the underlying ontological and axiological assumptions, reveals the extent of the divergence between the dominant paradigm and its alternatives, conceptualized as RI, that aspire to align the processes and outputs of innovation with social and ethical needs of the public.

Both "RI "and "RRI" are rich and multi-faceted concepts in the making, as attested by the various approaches these concepts have inspired. A historical analysis of the notion of innovation is revealing. Lucien von Schomberg and Vincent Blok's article begins by noting that the techno-economic concept of innovation emerged very late in history, in the nineteenth century to be more precise, and pushed aside a political understanding of innovation that goes back to the ancient Greeks. In antiquity, as well as during the Reformation, innovation meant a disruptive change in the established order, whereas for some Renaissance thinkers like Machiavelli and Bacon, it contributed to the stability of a society. Von Schomberg and Blok argue that while RRI reawakens the political meanings of innovation, which open up space for steering innovations into desirable directions in a responsible way, it faces a number of difficulties which we do not quite know how to solve. These range from the uncertainties innovations necessarily involve due to their open-ended nature, a point generally recognized in the innovation literature, to the virtual impossibility of achieving transparency required by RRI in the context of business firms who tend to be secretive for fear of losing their competitive edge.

One major way to guide innovations into desirable directions is to view the public as a bearer of interests and values and encourage participatory schemes that could serve to implement a dialog between science and society. In this vein, Janice Limson's article explores RRI learning activities and public engagement among biotechnology students in South Africa. The study she conducted sought to incorporate RRI, at an experimental basis, into higher education by having post-graduate students meet with members of the general public, as represented by grade 8-12 high school learners. The post-graduate students were interacting with their audience as scientists. This experience had a positive impact on them in that they were provided with a forum for practicing their communication skills and for reflecting on the broader meaning of their own research. The need to explain and contextualize one's own project created a sense of responsibility for the research endeavor. Generalizing this result suggests that directly engaging with the public holds important opportunities for scientists to appreciate doing research for social benefit. In other words, practicing to respond to the public tends to make scientists realize the value of RRI.

In a different vein, citizens can be seen as an epistemic resource when research endeavors matter to particular groups of people. It is in this context that the idea of lay-expertise has been introduced by Brian Wynne within the framework of local knowledge about long-term low-dose exposition to radioactive fallout in the vicinity of an atomic reprocessing plant (Wynne 1996). As Anke Bueter's contribution shows, the same idea of lay-expertise may apply to patients. More specifically, Bueter addresses the problem of psychiatric classification as it emerges with respect to the new Diagnostic and Statistical Manual of Mental Disorders, known as DSM-5. She explores ways to integrate patients into the process of forging diagnostic categories. 
Psychiatric disorders usually lack any clear-cut physiological indicators or accounts of how biological, social, and psychological quantities interact. In particular, the diagnostic categories in question go beyond the available evidence and include scientists' value-judgments, which are not necessarily in line with those of patients. One such instance is defining diagnostic thresholds that distinguish between what is considered normal and what is regarded as the manifestation of a disease. Another instance is the value-laden decision whether or not to regard symptoms such as Hyposexual Desire Disorder (HSDD) or Premenstrual Dysphoric Disorder (PMDD) as diseases. In such cases, people afflicted with certain symptoms can provide evidence from the first-person perspective and contribute to assessing the adequacy of the value-laden taxonomy. This inclusion of patients into the process of specifying psychiatric classification exceeds contributions to the research agenda and extends to judgments about justification. As such, it can also contribute to the reliability of the DSM's diagnostic categories, without which public trust in science would not be warranted.

In contrast to the situation several decades ago, science today is in need of earning the trust of the wider audience. Socially responsible research should provide reliable information and warrant public assent. Yet more is required if it is to merit public trust. Gürol Irzik and Faik Kurtulmus further advance on this route by considering conditions that are required by the public for investing warranted epistemic trust in science. To that end, they distinguish between two qualitatively different kinds of trust: basic and enhanced. Warranted epistemic trust in its basic form requires not only that research be reliable but also that the public has good reasons to believe so. Enhanced epistemic trust, on the other hand, appeals additionally to practical evaluations of inductive risks over and above basic trust. The inductive-risk argument says that in the absence of conclusive proofs, one may commit two kinds of errors: to mistakenly adopt a wrong hypothesis (false positive) or erroneously reject a truthful hypothesis (false negative). Rudner (1953) and Douglas $(2000,2009)$ recommend letting the practical damage done by an erroneous assessment influence the threshold of acceptance of the relevant hypothesis. As Irzik and Kurtulmus argue, science merits enhanced trust from the public if the practical damage done by a mistaken adoption of the hypothesis is judged by scientists and the public by approximately the same standards. They use their analysis of public trust to evaluate Kitcher's model of well-ordered science as it is developed in his (2011). They argue that Kitcher's model disregards the possibility that the public and scientists may judge inductive risks differently, as revealed by their analysis of the mumps-measles-rubella vaccination and autism controversy. The implication is that enhanced trust may not always obtain. They emphasize that, nevertheless, under such conditions a piece of scientific research can still merit basic epistemic trust on the part of the public, provided the public has good reasons to believe that the research has been conducted reliably. Yet this often requires appeal to second-order reasons regarding the trustworthiness of researchers - a point neglected by Kitcher.

Martin Carrier's paper contributes to the science-for-society wing of RRI or research done on behalf of society. That is, he stresses the outcome rather than the process dimension of RRI. One of the problems faced by such an endeavor is the difficulty of identifying or crafting a consensus about the common good. An even more demanding challenge is to devise projects that plausibly approach such shared social goals. Carrier suggests a number of pragmatic maxims that can reasonably be taken to promote 
the common good. These maxims all grow out of the principle that RRI strategies should seek to minimize the risks of damage while remaining flexible enough to take advantage of opportunities. One such maxim is to explore the social context in which a technology or procedure is introduced. For instance, one of the standards for judging the social impact of introducing GMOs is their bearing on local peasants. The question of whether such introduction strengthens or undermines their position vis-à-vis the globalized food industry can be answered without appeal to the biological features of GMOs. It is the present social conditions, rather than the future character of a technology, that determine its social evaluation.

Ibo van den Poel and Martin Sand address the responsibility of innovators as distinct from that of scientists and distinguish between backward-looking and forward-looking responsibilities of innovators. While the former include responsibilities such as blameworthiness, accountability, and liability, the latter include responsibilities such as obligation and virtue. They point out that the attribution of these responsibilities to innovators raises two difficult problems: under which conditions is it fair to attribute responsibility to them, and how effective is such attribution in improving technological development? They suggest several strategies to address these problems and argue that responsibility as accountability and as virtue are more important than other types of responsibility in relation to innovation. Accountability contributes to trust and facilitates learning from mistakes. Responsibility as virtue, on the other hand, expresses a willingness to take responsibility even if it is not fair to allocate responsibility to the agent concerned due to the uncertainties involved in the innovation process. This is a supererogatory virtue that is not morally required but still morally praiseworthy.

This special issue was inspired by a conference at the Center for Interdisciplinary Research (ZiF) at Bielefeld University in March 2017. But merely half of the papers assembled in this volume originated in this context. What drives this special issue is the general challenge to respond to the credibility crisis of science and to realign research with the seventeenth-century vision of knowledge suited to the betterment of the human condition. Socially responsible research is science with a human face. However, science also needs to retain its epistemic power and to provide dependable information. Socially responsible research is more than proceeding in harmony with public expectations. Responsibility also means not to comply with public wishful thinking. Responsible research cannot always be customer-friendly. RRI embodies a tension between serving people's aspirations and correcting people's expectations. This special issue is intended to explore the narrow pathway left open between these conflicting demands.

\section{References}

American, S. (2010). In science we trust. Scientific American, 303, 56-59.

Blok, V., \& Lemmens, P. (2015). The emerging concept of responsible innovation. Three reasons why it is questionable and calls for a radical transformation of the concept of innovation. In B.-J. Koops (Ed.), Responsible innovation 2: Concepts, approaches, and applications (pp. 19-35). Berlin: Springer.

Carrier, M. (2017). Facing the credibility crisis of science: On the ambivalent role of pluralism in establishing relevance and reliability. Perspectives on science, 25, 439-464.

Douglas, H. (2000). Inductive risk and values. Philosophy of Science, 67, 559-579. 
Douglas, H. (2009). Science, policy, and the value-free ideal. Pittsburgh: University of Pittsburgh Press.

European Commission. (2010). "Science and technology report. Special Eurobarometer 340/Wave 73.1TNS Opinion and Social."<ec.europa.eu/public_opinion/archives/ebs/ebs_340_en.pdf >.

Kitcher, P. (2001). Science, truth, and democracy. Oxford: Oxford University Press.

Kitcher, P. (2011). Science in a democratic society. Amherst: Prometheus.

Kourany, J. A. (2003). A philosophy of science for the twenty-first century. Philosophy of Science, 70, 1-14. Kourany, J. A. (2010). Philosophy of science after feminism. Oxford: Oxford University Press.

Macnaghten, P. (2016). Responsible innovation and the reshaping of existing technological trajectories: The hard case of genetically modified crops. Journal of Responsible Innovation, 3, 282-289.

Rudner, R. (1953). The scientist qua scientist makes value judgments. Philosophy of Science, 20, 1-6.

Stilgoe, J., Owen, R., \& Macnaghten, P. (2013). Developing a framework for responsible innovation. Research Policy, 42, 1568-1580.

Van den Hoven, M. J. (2014). Responsible innovation: A new look at technology and ethics. In M. J. van den Hoven, N. Doorn, T. Swierstra, B.-J. Koops, \& H. Romijn (Eds.), Responsible innovation 1 (pp. 3-13). Netherlands: Springer.

von Schomberg, R. (2013). A vision of responsible innovation. In R. Owen, M. Heintz, \& J. Bessant (Eds.), Responsible innovation: Managing the responsible innovation of science and innovation in society (pp. 51-74). London: John Wiley.

Wissenschaft im Dialog/Kantar Emnid (eds.) (2017). Wissenschaftsbarometer 2017. www. wissenschaftsbarometer.de.

Wynne, B. (1996). "May the sheep safely graze? A reflexive view of the expert-lay knowledge divide. In S. Lash, et al. (Eds.), Risk, environment, and modernity. Towards a new modernity (pp. 44-83). London: Sage.

Publisher"s Note Springer Nature remains neutral with regard to jurisdictional claims in published maps and institutional affiliations. 